\title{
EFFECT OF ADITIVE PRODUCTION ON AISI 316L MATERIAL PROPERTIES
}

\author{
'Šárka HERMANOVÁ, ${ }^{1}$ Petr ČížEK, 'Gabriela ROŽNOVSKÁ, ${ }^{1} J a n a$ KOSŇOVSKÁ \\ ${ }^{1}$ MATERIAL AND METALLURGICAL RESEARCH Ltd., Ostrava, Czech Republic, EU, \\ sarka.hermanova@mmvyzkum.cz
}

https://doi.org/10.37904/metal.2020.3499

\begin{abstract}
This work is focused on the study of influence of additives manufacturing on material properties of AISI 316L steel. Comparison of the material properties of the plate produced by the selective laser melting (SLM) technology and the hot-rolled plate was performed not only on the results of tensile tests, but also on small punch tests, which is an evolving and promising testing method and will be implemented into standardized testing methods within EU soon. The determination of the yield point and the tensile strength from the results of small punch tests is based on the simple correlation among them. For wrought steels this correlation was verified but no such a relation is known for additive steels. Therefore, we tried to use this correlation to additive manufactured material and to compare the obtained results with the results of conventional tensile tests. The results of mechanical testing are complemented by microstructural investigation of both technologies, including fractographic analysis of fracture surfaces.
\end{abstract}

Keywords: Metallurgy, additive manufacturing, steel AISI 316L, mechanical properties, Small punch tests

\section{INTRODUCTION}

This article is focused on the effect of additive production on material properties of AISI 316L, comparison with wrought steel of the same grade and exploration the possibility of using small punch test for verifying of mechanical properties of 3Dprinted steels. The reason is that additive manufacturing is in this century the most developing technology and still is not enough information about properties of 3D printed steels.

Additive manufacturing widely known also as 3D printing is relatively new technology. Additive manufacturing is a process of creating a three-dimensional object from a digital file. It was at first applicated for plastic material and for producing models and prototypes. History of this process is described for instance in [1]. There exist many types of additive manufacturing process. One of them is metal powder bed fusion technology, as classified the International Committee ASTM F42 and is included in ISO/ASTM 52900:2015 standard. And a part of them is Selective laser melting technology what is used for produce the experimental material.

Selective laser melting (SLM) technology is a technique designed to use a high power-density laser to melt and fuse metallic powders together [2]. This technology can be used for special production in aerospace or automotive components especially in the cases when it is difficult to manufacture them by other techniques, it means everywhere where it is economical and where the properties are satisfactory.

As the principal advantage of SLM technology lies in producing small and complex products, when the material properties cannot be tested by standardized test specimens it would be convenient to have another possibility how to study the mechanical properties either in the as-received state, or even under operating condition.

One way how to test small size components is using small punch test (SPT) method. SPT testing is a progressive testing method of miniature test samples and is very often used for instance in nuclear and coal power stations for determining residual lifetime of the key pressurized parts. It is applicated to determining the mechanism of failure and damage of the equipment, too $[3,4,5]$. Our company has already extensive 
experience with this method. But to the author's knowledge, there is no information about the use of this method in practice for additive produced materials.

Impact and tensile tests of both the full-sized and small punch test specimens were used to study the material properties of a steel produced by 3D printing, as well as a to assess the possibility of using and interpretation of the SPT results for 3D printed material. There is a lot of information about the influence of purity (especially porosity), printing (building up) direction, velocity and laser power on material properties of intentionally prepared test specimens but hardly any about properties of the real products. The aim of this work is, therefore, to investigate the behaviour of austenitic steel produced by 3D printing and to compare its properties with a rolled sheet of the same material as well as to verify whether small punch testing can be used to determine material properties of 3D printed steels.

As is generally known, steel produced by 3D printing contains depending on the technology, more or less pores, which have a significant effect on the brittle-fracture properties of steel. The steel produced by SLM technology also has a special texture and the microstructure is very similar to welds. [2] Therefore the properties of SLM steel were verified in several directions. The results of mechanical testing are complemented by microstructural investigation including fractographic analysis of fracture surfaces.

\section{EXPERIMENT}

The experimental material was plate produced by additive manufacturing process - selective laser melting. Powder named SS 316L-0407 determined for additive manufacturing from Renishaw company was used for producing 3D printed "plate" with dimension of base $15 \mathrm{~mm} \times 280 \mathrm{~mm}$ and height $170 \mathrm{~mm}$. The powder is designed for 3D printing by SLM technology with $200 \mathrm{MW}$ laser power and for layer thickness $50 \mu \mathrm{m}$.

\subsection{Chemical composition}

The chemical composition of powder used for 3D printing is stated in Table 1. The second evaluated material was wrought steel plate with thickness $15 \mathrm{~mm}$ delivered in solution annealed condition. Comparison of chemical composition of powder, 3D printed material and wrought steel is stated in Table 1.

Table 1 Chemical composition of powder SS 316L-0407, 3D printed steel and plate

\begin{tabular}{|c|c|c|c|c|c|c|c|c|c|c|c|c|}
\hline \multirow{2}{*}{\begin{tabular}{|c} 
Element /Type \\
of product
\end{tabular}} & \multicolumn{12}{|c|}{ Concentration (wt\%) } \\
\hline & C & Mn & $\mathrm{Si}$ & $\mathbf{P}$ & $\mathbf{s}$ & $\mathrm{Cu}$ & $\mathrm{Ni}$ & $\mathrm{Cr}$ & Mo & $\mathbf{v}$ & 0 & $\mathbf{N}$ \\
\hline Powder & $\leq 0.03$ & $\leq 2.00$ & $\leq 1.00$ & $\leq 0.045$ & $\leq 0.030$ & - & \begin{tabular}{|c|}
10.00 to \\
14.00 \\
\end{tabular} & \begin{tabular}{|c|}
16.00 to \\
18.00 \\
\end{tabular} & $\begin{array}{c}2.00 \text { to } \\
3.00\end{array}$ & - & $\leq 0.10$ & $\leq 0.10$ \\
\hline $\begin{array}{c}\text { 3D printed } \\
\text { steel }\end{array}$ & 0.025 & 0.490 & 0.660 & 0.0160 & 0.0050 & 0.110 & 12.700 & 16.600 & 2.360 & 0.0390 & 0.0010 & $<0.0010$ \\
\hline Plate & 0.019 & 1.851 & 0.265 & 0.0372 & 0.0014 & 0.305 & 10.001 & 16.986 & 2.022 & - & - & 0.0298 \\
\hline
\end{tabular}

Chemical composition of 3D printed plate completely conforms with the requirements for the steel AISI $316 \mathrm{~L}$ with low trace elements and even gases $(\mathrm{O}, \mathrm{N})$.

\subsection{Tensile test and Charpy V-notch test}

Test specimens for tensile tests and Charpy $V$-notch tests were machined in longitudinal $(L)$ and transverse (T) direction in both experimental materials. All test results performed on conventional test specimens are shown in Table 2 and Figure 1.

While the material properties of hot rolled plate are in both directions practically identical, there is a drop in either yield stress either tensile strength in transverse direction in 3D printed material. Even more pronounced 
decrease was detected in plasticity and notch toughness, when elongation of 3D printed material was only more than half of the value in longitudinal direction and even a quarter in transverse direction compared to the hot rolled plate.

Table 2 Results of material properties testing

\begin{tabular}{|c|c|c|c|c|c|c|}
\hline \multirow{2}{*}{ Material } & Direction & $\begin{array}{c}\mathbf{R}_{\mathbf{p} 0,2} \\
(\mathbf{M P a})\end{array}$ & $\begin{array}{c}\mathbf{R}_{\mathbf{m}} \\
(\mathbf{M P a})\end{array}$ & $\begin{array}{c}\mathbf{A} \\
(\%)\end{array}$ & $\begin{array}{c}\mathbf{Z} \\
(\%)\end{array}$ & $\begin{array}{c}\mathbf{K V} \\
(\mathbf{J})\end{array}$ \\
\hline \multirow{2}{*}{$3 \mathrm{D}$} & $\mathrm{L}$ & 557.1 & 676.6 & 46.5 & 59.5 & 66.0 \\
\cline { 2 - 7 } & $\mathrm{T}$ & 472.8 & 591.1 & 21.5 & 34.5 & 82 \\
\hline \multirow{2}{*}{ Plate } & $\mathrm{L}$ & 258.8 & 643.9 & 79.2 & 80.6 & 394 \\
\cline { 2 - 7 } & $\mathrm{T}$ & 257.9 & 642.9 & 76.2 & 81.6 & 298 \\
\hline
\end{tabular}

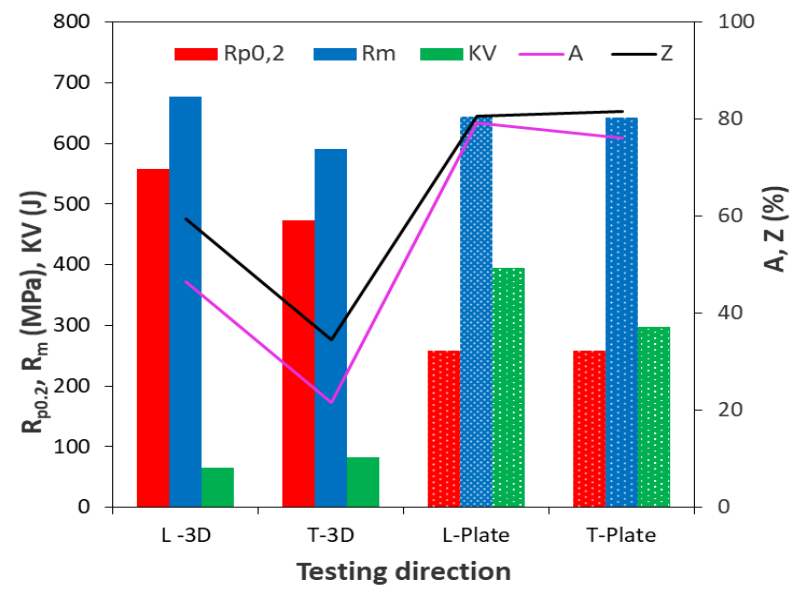

Figure 1 Results of mechanical tests of 3D printed steel AISI 316L

\subsection{Small punch tests}

The method of testing of SPT was described in [6]. Five discs shaped specimens $8 \mathrm{~mm}$ in diameter and 0.5 $\mathrm{mm}$ in thickness were prepared from 3D printed material in three directions - longitudinal (C), transverse (B) and surface (A), see Figure 2. SPT samples of hot-rolled plate were machined in the axis of longitudinal direction because of homogenous properties in each direction as is visible form tensile tests. Table 2. Five SPT specimens were prepared and tested in order to obtain the information about the scatter of results. (Figure 3)

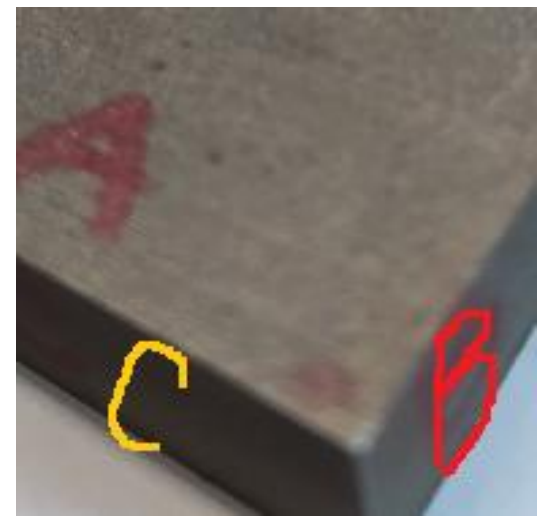

Figure 2 Testing directions of 3D

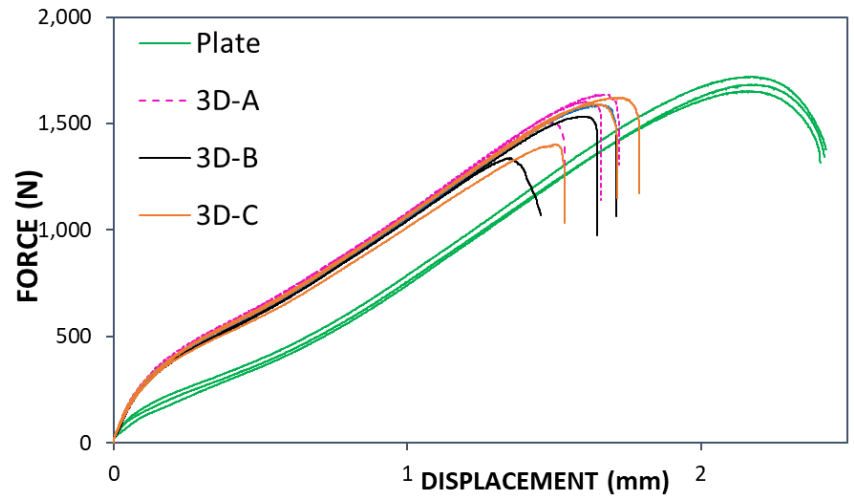

Figure 3 Chart of SPT of 3D printed steel and hot rolled plate of AISI 316L steel 

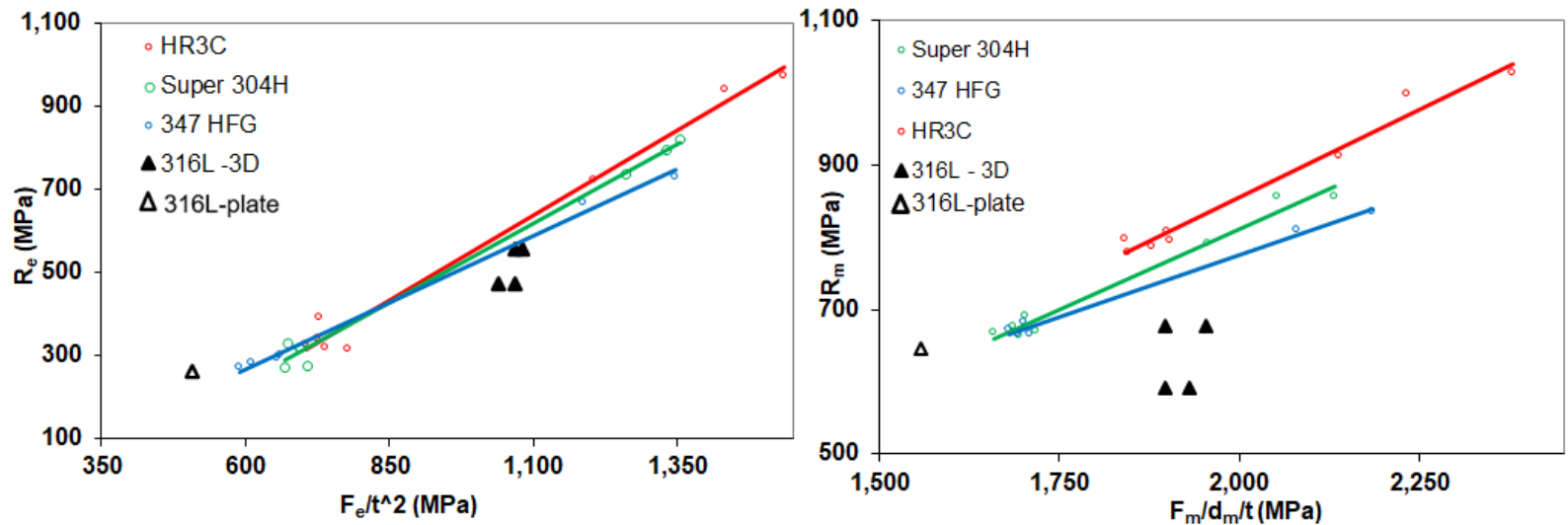

Figure 4 Relation between yield strength and adequate parameters of SPT tests for 3D printed steel AISI $316 \mathrm{~L}$ and other austenitic steels

\subsection{Analysis of microstructure}

Microstructure was studied in three direction (the same as in the case of SPT). Figure $\mathbf{5}$ shows the austenitic banded microstructure looking in the transverse direction like beads with pores and balls of unmelted powder.
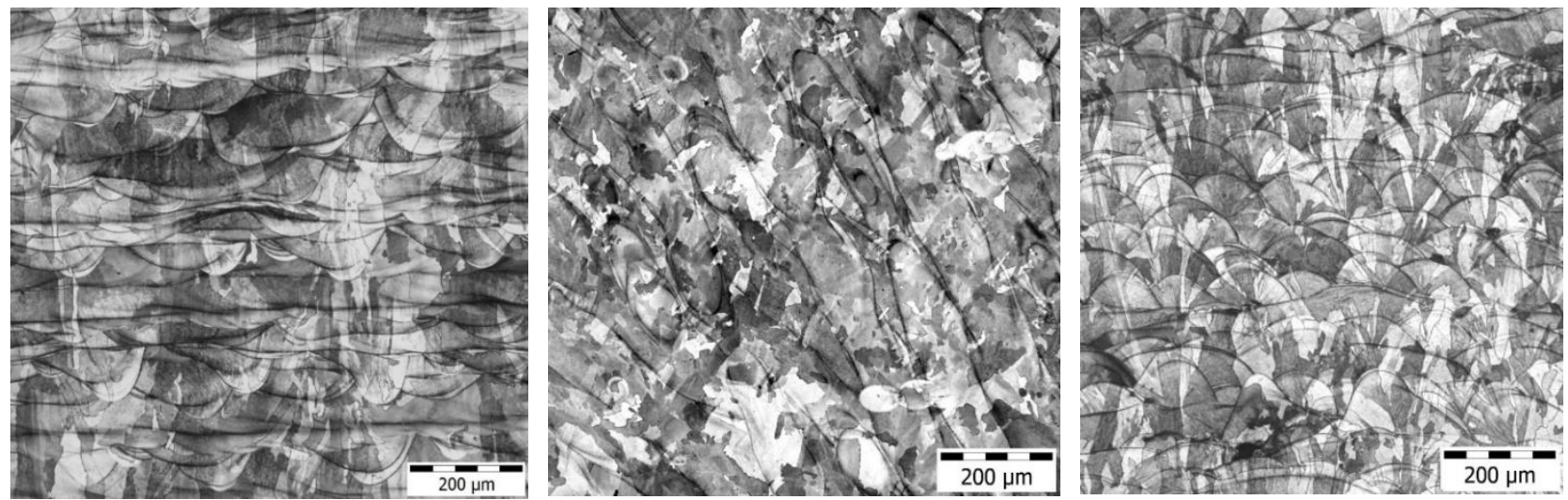

Figure 5 Microstructure of 3D printed AISI 316 steel in three direction: left from the surface, in the middle longitudinal direction, right transverse direction

Fractographic investigation was performed on the fracture surface of the 3D printed Charpy test specimens. Fracture surface was predominantly formed by transgranular ductile fracture with a hole morphology. (Figure 6 and Figure 7)
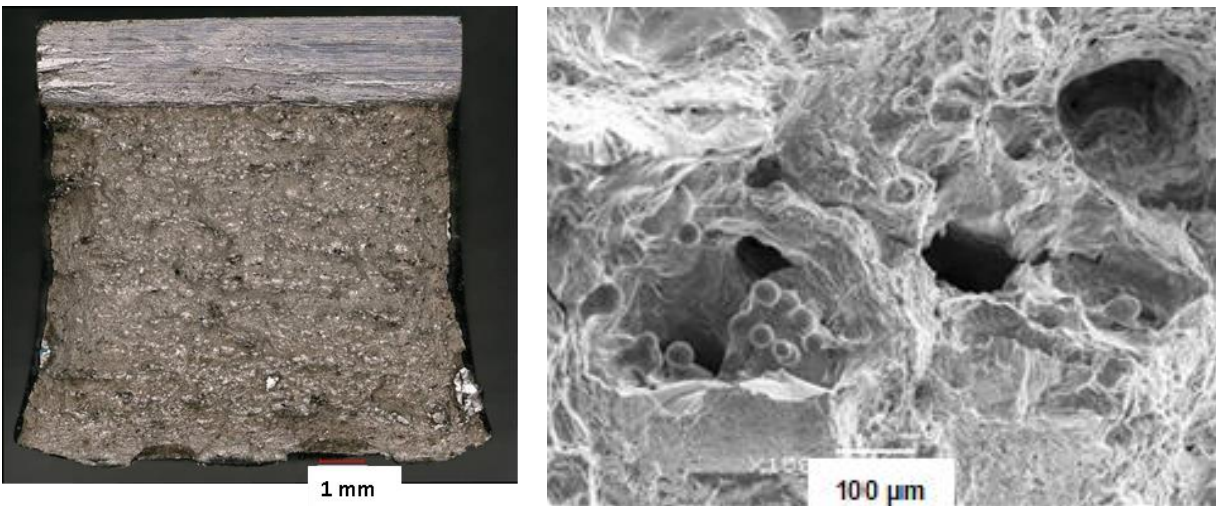

Figure 6 Fractography of 3D printed AISI 316L - transverse direction 

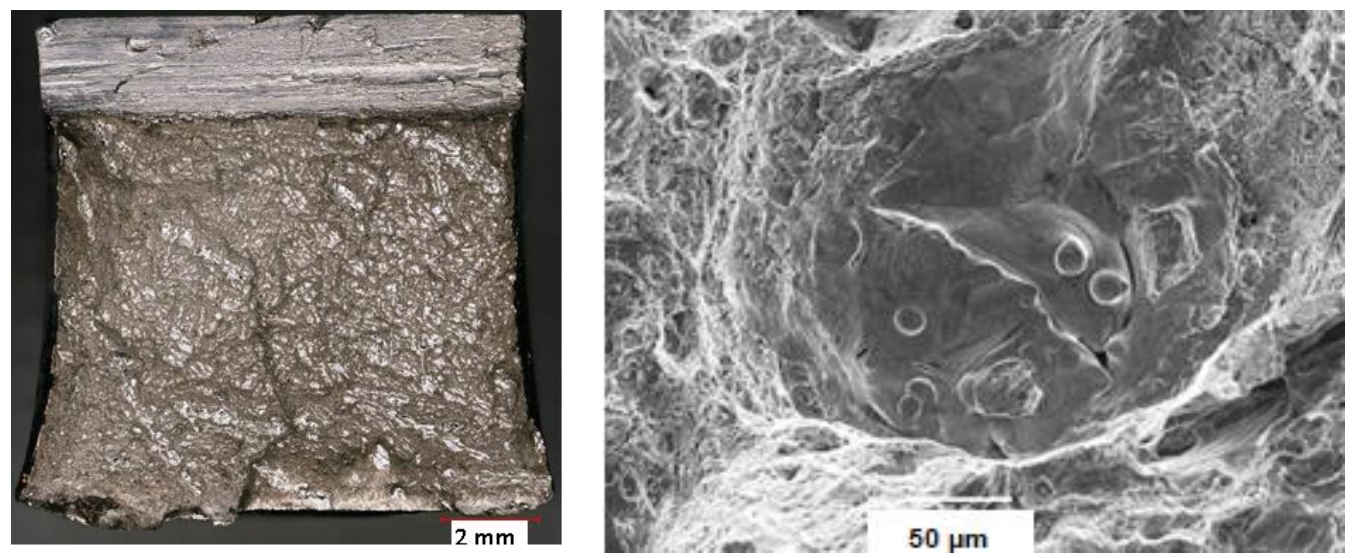

Figure 7 Fractography of 3D printed AISI 316L - L direction

\section{RESULTS AND DISCUSSION}

The results of mechanical tests including SPT show that 3D printed material has higher yield stress and well comparable tensile strength to hot rolled plate of the same steel, but significantly lower plasticity and fracture toughness. The area under the curves for SPT curve (Figure 3) representing fracture energy is less for 3D printed steel as for rolled plate. The decrease of fracture energy of SPT (ESP) of 3D material versus plate is about $22 \%$. SPT curves also show a large scatter of results, especially for samples taken perpendicularly to the print base. On the other hand, the smallest scatter was found in samples taken parallel to the plate surface, i.e. just the same orientation like material sampled in-situ from the real surface of an in-service component. The reason for such a behaviour is probably in printing technology as can be seen in microstructure and on the fracture surface. (Figures 5-7) There were observed numerous shrinkage holes, pores and unmelted metal balls in 3D printed material. SLM technology with $200 \mathrm{~W}$ power laser does not seem to be powerful enough for such demanded conditions. Laser with higher power should be more suitable in order to completely melt all particles of metal powder and/or application of Hot Isostatic Pressing or other advanced technology.

The results obtained in our research were added to the graph of the dependence of yield stress and tensile strength on the corresponding parameters of SPT tests (Figure 4). Although it seems that in the case of the yield stress dependence, the results of 3D printed material could complement the existing linear dependence valid for various austenitic steels, (Figure 4 - left), in the case of the correlation of the tensile strength it turned out that this is not possible, the results obtained for 3D printed material lies significantly below the existing dependencies (Figure 4 - right). The obtained results thus showed that the correlation curves routinely applied in small punch testing of wrought austenitic steels for determining yield stress and tensile strength cannot be used for 3D printed material.

\section{CONCLUSION}

This work was focused on the study of the influence of the production of additive manufacturing on material properties of AISI $316 \mathrm{~L}$ steel. We compared the material properties of the plate produced by the selective laser melting technology and the hot-rolled plate by tensile tests, impact tests and small punch tests. We tried to determine the yield strength and tensile strength from the results of small punch tests. Due to the large variance of values which is related to the results of the metallographic investigation and very high divergence of tensile strength of 3D printed steel to other conventual austenitic steels, it is not possible to use the current correlation and it is appropriate to obtain more results, e.g. from different technological conditions of 3D printing including HIP processing. 


\section{ACKNOWLEDGEMENTS}

This work presents some results of the project No. CZ.02.1.01/0.0/0.0/17_049/0008399 funded from the EU and CR financial funds provided by the Operational Program Research, Development and Education, Call 02_17_049 Long-Term Intersectoral Cooperation for ITI, Managing Authority: Czech Republic - Ministry of Education, Youth and Sports.

\section{REFERENCES}

[1] GU, D. D, MEINERS, W., WISSENBACH, K., POPRAWE, R. Laser additive manufacturing of metallic components: materials, processes and mechanisms. International Materials Reviews. 2012, vl. 57, no.3, pp. 133164.

[2] $\mathrm{CHOO}, \mathrm{H}$., et.al. Effect of laser power on defect, texture, and microstructure of a laser powder bed fusion processed 316L stainless steel. Materials and Design. 2019, vol. 164, Article 107534

[3] LUCON, E. 1.08 - Testing of Small-Sized Specimens. Comprehensive Materials Processing. 2014, vol. 1, pp. 135-163.

[4] KUBOŇ, Z., STEJSKALOVÁ, Š., KANDER, L. Effect of Sigma Phase on Fracture Behavior of Steels and Weld Joints of Components in Power Industry Working at Supercritical Conditions (Chapter4), Austenitic Stainless Steels - New Aspects. Borek, W., Tanski, T., Brytan, Z. (Eds.). December 2017. Rieka: InTech.2017, pp. 63-92.

[5] HOLMSTRÖM, S., et al. Creep strength and minimum strain rate estimation from Small Punch Creep tests. Materials Science and Engineering. 2018, vol. 731A, pp. 161-172.

[6] MATOCHA, K., KANDER, L., DORAZIL, O., GUAN, K., XU, Y. The Evaluation of Actual Material Properties of Low Alloy CrMoV Steel from the Results of Small Punch Tests. Procedia Materials Science. 2016, vol. 12, pp. $1-6$. 